\title{
Килина А.А. \\ Роль и место региональных органов государственной власти в привлечении денежных средств населения
}

doi: $10.18411 / \mathrm{lj}-02-2021-83$

idsp: ljournal-02-2021-83

\section{Аннотация}

В целях развития экономики Российской Федерации, отдельных субъектов федерации в частности, а также преодоления кризисных влияний, которые негативно влияют на риски нестабильности внешней экономики, важным направлением является привлечение денежных средств населения. Данная статья направлена на исследование действующей системы привлечения денежных средств населения, a также формирование оптимальной системы влияния региональных органов государственной власти на систему привлечения денежных средств населения.

Ключевые слова: денежные средства, Центральный банк, региональные органы власти, коммерческие банки, население, банковская система, сбережения, привлечение средств.

\section{Abstract}

For the development of the Russian economy, as well as its individual subjects, it is important to ensure the attraction of funds from the population. This allows, as a rule, to overcome crises that negatively affect the stability of the economy. This article is devoted to the study of the system of attracting money from the population. It includes a scheme of the influence of regional government bodies on the system of attracting funds from the population.

Keywords: cash, Central Bank, regional authorities, commercial banks, population, banking system, savings, fundraising.

В рамках российской действительности, роль государства является крайне высокой, причем в последнее время она становится все более значимой с учетом усиления влияния кризисных явлений и в условиях проблем территориального развития отдельных регионов страны. В России с начала 90-х годов развивается рыночная экономика, которая характеризуется институциональной системой развития, включая обеспечение прав собственности, их передачу, а также политические, правовые, а также экономические механизмы принятия решений.

Рассматривая денежно-кредитную систему, развивающуюся в рамках рыночной экономики, можно сказать, что ее функции являются достаточно узкоспециализированными. При этом основным органом в рамках данной системы является Центральный банк РФ. Другим элементом системы является целая система коммерческих банков, ведущих свою деятельность на территории России. В рамках данной системы происходит фактически процесс привлечения денежных средств.

Отметим, что Центральный банк РФ представляет собой независимое учреждение, основанное правительством и контактирующее напрямую с коммерческими банками, а не населением. Основная функция деятельности Центрального банка заключается в сохранении стабильности денежно-кредитной системы, защиты от кризисов и регулирование денежного предложения на основе изменения экономической ситуации в стране [5, с. 63].

В свою очередь, коммерческие банки на основе лицензии Центрального банка фактически осуществляют прямой контакт с населением и предприятиями, принимая у последних денежные средства на процентные вклады и выдавая кредиты под проценты заемщикам. Основная цель деятельности коммерческих банков отличается от Центрального банка. В данном случае коммерческие банки преследую цель - 
получение максимально возможной прибыли, ввиду чего банки значительно стараются расширить состав оказываемых услуг. От основной деятельности прибыль банки получают как разница между полученными и выплаченными процентами.

Кроме кредитных операций, банки также реализуют платежно-расчетные операции, которые, как правило, являются самыми масштабными в рамках их хозяйственной деятельностью. Также не меньшую долю занимают и прочие услуги, включая следующие: управление ценными бумагами физических и юридических лиц, консультирование, бюджетное и налоговое планирование, а также прочие услуги, которые также приносят дополнительный доход банкам.

Основа обеспечения деятельности денежно-кредитной системы связана с динамикой показателя денежного мультипликатора, который отражает в себе потенциал увеличения банками собственных кредитных ресурсов, то есть расширения денежной массы. Основная необходимость эмиссии денежных средств и привлечения денежных средств населения состоит в том, что прирост сумм депозитов в банке позволяет в свою очередь расширять его деятельность путем выдачи еще больших объемов кредитов. При получении (при проведении собственных хозяйственных операций, смены владельцев денежных средств) новых кредитов в виде денежных средств, они, по своей сути, могут быть также направлены в депозит в другом банке, который затем повторив данные операции получит возможность выдать новые кредиты и так далее.

Законодательно установлено в целях стабилизации денежно-кредитной системы обязательное наличие резервов банками, которые отчисляются за счет средств, внесенных на банковские счета и не выданных в качестве кредитов. Данное обязательство обуславливается требованиями Центрального банка РФ.

Избыточные резервы банка представляют остаточную наличность банка после отчислений обязательных резервов. Именно данная сумма банком может быть выдана заемщикам в качестве кредита. Тем самым, можно сделать вывод, что обязательные резервы представляют собой инструмент, при помощи которого Центральный банк РФ реализует функцию управления коммерческими банками и влиять на их способность к выдаче кредитов. Важно отметить, что обязательные резервы не представляют собой дополнительный вид ликвидности для коммерческих банков, которыми они могут в любой момент воспользоваться, а выступают именно в качестве показателя их устойчивости и стабильности денежно-кредитной системы в целом.

Государство напрямую оказывает влияние на предложение денег в экономике и осуществляет регулирование денежной массы. Таким образом, с учетом вышесказанного, в организации предложения денежных средств в России участвуют [3, c. 286]:

1) Центральный банк;

2) коммерческие банки;

3) население.

Центральный банк РФ, занимая главенствующее положение, осуществляет непосредственное регулирование и контроль предложения денег через их эмиссию. Также Центральный банк управляет так называемой ключевой ставкой, увеличивая предложение кредитных денежных средств снижая уровень ставки, или наоборот, сокращая предложение, увеличивая уровень ставки.

В случае если представить в качестве денежной массы всю сумму наличных денег и имеющихся депозитов (включая все остатки на счетах), то модель денежного предложения может быть выражена следующим образом. В составе экономики, кроме наличных денег, часть доходов экономические субъекты переводят во вклады (депозиты) коммерческим банкам. В свою очередь, банки непосредственно получая денежные средства, направляют их на выдачу кредитов заемщиков, обеспечивая при этом процесс мультипликативного прироста денежной массы. 
Сумма денежного предложения находится в прямой зависимости от суммы денежной базы, а также одновременно находится в обратной зависимости от коэффициента депонирования и нормы резервирования. В частности, последние два показателя представляют оценку избыточных резервов и являются фактически убывающими функциями от непосредственной ставки процента (ввиду того, что увеличение процентных ставок приводит к сокращению уровня избыточных резервов ввиду улучшения привлекательности кредитов для коммерческих банков). В рамках населения, увеличение процентной ставки соответственно увеличивает привлекательность депозитов и снижает долю наличных денежных средств.

В свою очередь, спрос на денежные средства отражает собой желание населения обладать в текущий момент времени определенной суммой денег. Тем самым спрос на деньги является достаточно фиксированной величиной. В рамках теоретических и практических особенностей анализа денежного спроса отдельными ученымиэкономистами вырабатываются различные методики, основывающиеся на концепциях спроса на деньги. Наиболее известными из них можно выделить следующие [1, с. 361]:

1) классическая концепция;

2) теория Дж. М. Кейнса;

3) модели У. Баумоля - Дж. Тобина.

Вторая и третья модели предполагают, что спрос на деньги должен исследоваться со стороны возможностей оптимизации денежного запаса экономического субъекта. В свою очередь, также существуют портфельные теории, в которых спрос на деньги связывается напрямую со спросом на остальные важнейшие виды активов. В данной части наиболее значимым направлением анализа спроса является монетаризм. Первым из ученых-исследователей теории спроса на деньги непосредственно функцию денежного спроса предложил М. Фридман. Согласно автору, спрос на денежные средства - это функция включающая в себя набор следующих переменных: уровня цен, доходности по акциям и облигациям (за вычетом значения инфляции), совокупного богатства, которое исчисляется в соответствии с концепцией перманентного дохода. В свою очередь, оценка влияния на денежный спрос может быть охарактеризована следующим образом: увеличение уровня цен влечет к увеличению суммы спроса на реальные денежные остатки, и наоборот. При этом увеличение динамики инфляции приводит, наоборот, к сокращению реальной ценности денег и увеличению ценности реальных благ, что в свою очередь влечет к так называемому «бегству от денег».

Спрос на денежные средства в некоторой степени является также значением спроса на деньги как средства сбережения. Деньги население о организации могут направлять в различные финансовые активы: в финансовые инструменты (акции, облигации и прочие), наличные деньги, вклады. При этом хранение денег сопровождается также с их постепенной потерей ввиду снижения их покупательской способности, что в свою очередь определяет издержки упущенных возможностей. При этом можно выделить следующую зависимость: чем более высокой является процентная ставка по текущим вкладам, тем менее выгодным является хранение денежных средств как запаса наличных.

То есть в случае, если спрос на деньги для сделок является достаточно устойчивой величиной, не зависящей от процентных ставок, то спрос на деньги для сбережений напрямую зависит от ставки процента. Причем чем выше ставка, тем более дорогим становится хранение запасов денежных средств и тем ниже становится спрос на денежные средства.

Спрос и предложение на денежные средства со стороны населения объединяется на так называемом денежном рынке. На данном рынке, в частности, устанавливается денежное равновесие, подобное товарным рынкам, когда происходит пересечение кривой спроса на денежные средства и линии их предложения. Само пересечение 
определяет равновесную ставку процента, которая и представляет фактическую стоимость денег.

С учетом вышеприведенного, можно сделать вывод, что денежные средства населения в своей совокупности представляют собой часть денежно-кредитной системы, эффективность функционирования которой находится в прямой зависимости от объема и скорости их оборачиваемости в деловом обороте.

Процесс совершенствования денежного обращения в России способствуют ее активному развитию в соответствии с парадигмой рыночной экономики. В данной части все более самостоятельных функций передается регионам и органам местного самоуправления. При этом до сих пор является достаточно значимой проблемой недостаток финансовых ресурсов для должного управления денежным обращением конкретно в регионах и в сферах обязанностей органов местного самоуправления.

На основании приведенной информации предложим рекомендуемую схему влияния региональных органов государственной власти на систему привлечения денежных средств населения на рисунке 1 .

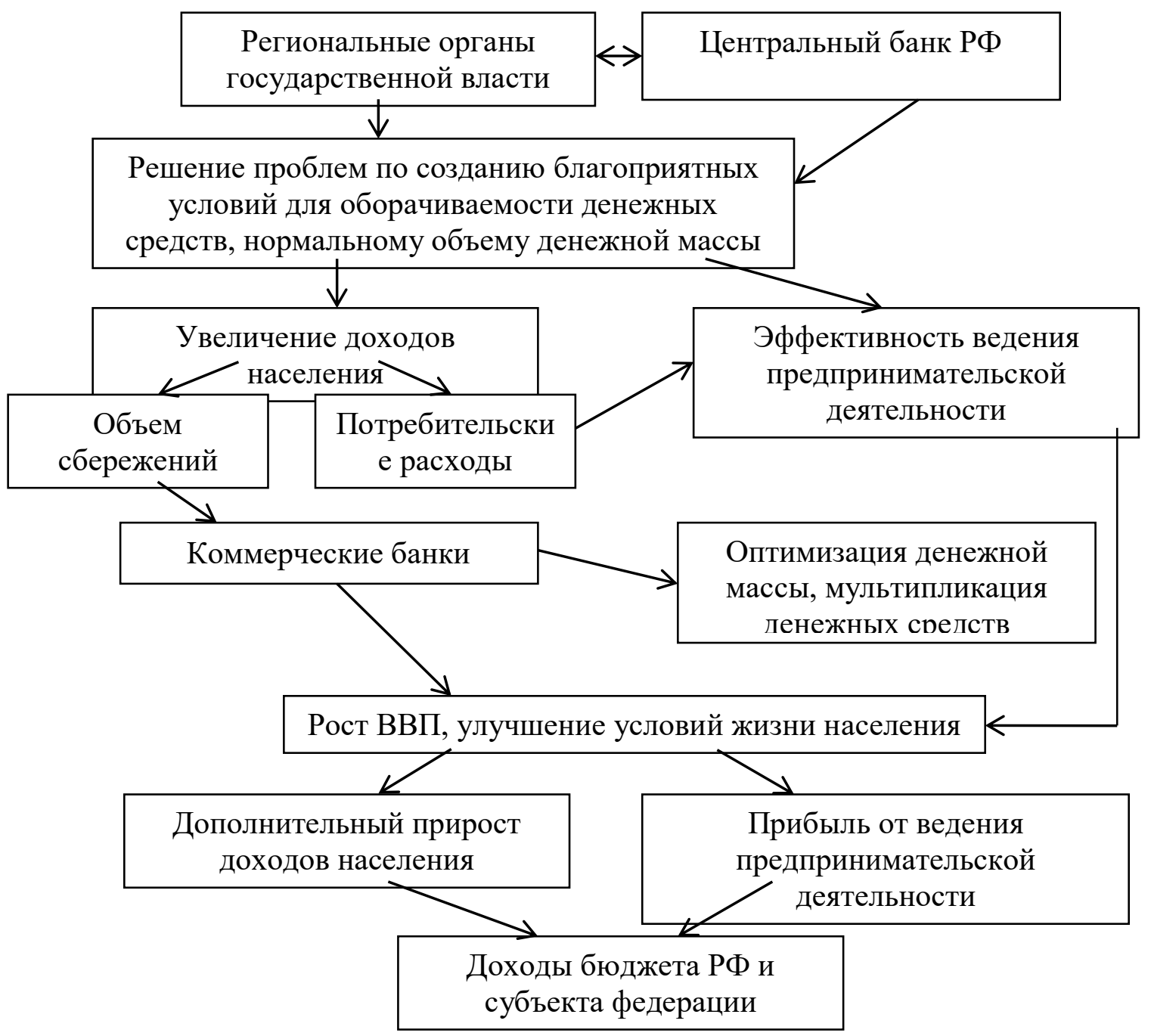

Рисунок 1 - Рекомендованная схема влияния региональных органов государственной власти на систему привлечения денежных средств населения

По нашему мнению, основная цель региональных органов государственной власти в привлечении денежных средств населения заключается в организации наиболее благоприятной среды в целях повышения эффективности оборачиваемости денежных средств. В данной части, предполагается, что органы государственный 
власти должны осуществлять поиск решений проблем, включая, например, обеспечение благоприятных внешних условий для эффективного использования денежных средств, их оборачиваемости, объема денежной массы. Региональная финансовая система выступает как система управления денежными средствами целой цепочки взаимосвязанных хозяйствующих субъектов и оборотом денежных средств населения региона. Здесь свою регулирующую роль должны играть региональные и местные органы власти. В частности это - поддержание интеграции хозяйственных интересов по «щепочкам приращения стоимости» регионально значимых продуктовых направлений с целью максимальной эффективности производства такой продукции. Еще одним важным моментом является создание положительной репутации в обществе от улучшения внешней среды и качества жизни населения.

В случае если основной спектр задач по управлению денежным обращением будет переложен на региональные органы власти, то это может обеспечить высокую вероятность того, что поддержка региональных предпринимателей, находящихся в кризисном положении, будет осуществляться более оптимально и обоснованно. Ввиду этого эффект от привлечения денежных средств региона будет кумулятивным за счет отсутствия ситуации, когда денежные средства будут задерживаться во владении посредников, не занимающихся напрямую производственной деятельностью. Это позволит в конечном итоге обеспечить развитие всего региона в целом и в конечном итоге улучшит положение самого населения.

$$
* * *
$$

1. Галанов В.А. Финансы, денежное обращение и кредит: учебник / В.А. Галанов. -2 -е изд. - М.: ИНФРА-М, 2017. - $414 \mathrm{c.}$

2. Гояев А.М. Современная проблематика инструментов привлечения денежных средств населения во вклады коммерческих банков // Научная дискуссия: инновации в современном мире. - 2017. - № 11. - C. $41-46$

3. Колпакова Г.М. Финансы, денежное обращение и кредит: учебник / Г.М. Колпакова, Ю.В. Евдокимова. - 5-е изд., перераб. и доп. - М.: ИНФРА-М, 2019. - 609 с.

4. Сафиуллин А.Р. Формирование благосостояния населения: современные тенденции и Россия: Монография / А.Р. Сафиуллин - М.: ИЦ РИОР, НИЦ ИНФРА-М, 2019. - 215 с.

5. Стародубцева Е.Б. Основы банковского дела: учебник / Е.Б. Стародубцева. - 2-е изд., перераб. и доп. - М.: ИД «ФОРУМ» : ИНФРА-М, 2018. — 288 c.

\section{Килина А.А. \\ Современное состояние системы привлечения денежных средств населения на российском рынке}

doi: $10.18411 / \mathrm{lj}-02-2021-84$

idsp: ljournal-02-2021-84

\section{Аннотация}

На сегодняшний момент у России имеется достаточно четко сформированная финансовая система. В тоже время сохраняется проблема трансформации денежных средств в инвестиционные проекты и их своевременное привлечение в развитие экономики РФ. Ввиду этого, в статье рассмотрено современное состояние системы привлечения денежных средств населения, а также дана оценка ее возможности дальнейшего развития.

Ключевые слова: денежные средства, Центральный банк, коммерческие банки, население, банковская система.

\section{Abstract}

Today, Russia has a fairly well-formed financial system. At the same time, the problem of transforming funds into investment projects and their timely involvement in the development of the Russian economy remains. In view of this, the article examines the 